\title{
Prednisolone is associated with a worse bone mineral density in primary adrenal insufficiency
}

\author{
Kathrin R Frey ${ }^{1}$, Tina Kienitz², Julia Schulz², Manfred Ventz ${ }^{2}$, Kathrin Zopf ${ }^{2}$ and Marcus Quinkler ${ }^{3}$ \\ ${ }^{1}$ Department of Medicine I, Endocrine and Diabetes Unit, University Hospital, University of Würzburg, Würzburg, Germany \\ ${ }^{2}$ Charité - Universitätsmedizin Berlin, Corporate Member of Freie Universität Berlin, Humboldt-Universität zu Berlin, and Berlin Institute of Health, \\ Berlin, Germany \\ ${ }^{3}$ Endocrinology in Charlottenburg, Berlin, Germany
}

Correspondence should be addressed to M Quinkler: marcusquinkler@t-online.de

\begin{abstract}
Context: Patients with primary adrenal insufficiency (PAI) or congenital adrenal hyperplasia (CAH) receive life-long glucocorticoid (GC) therapy. Daily GC doses are often above the physiological cortisol production rate and can cause long-term morbidities such as osteoporosis. No prospective trial has investigated the long-term effect of different GC therapies on bone mineral density (BMD) in those patients.

Objectives: To determine if patients on hydrocortisone $(\mathrm{HC})$ or prednisolone show changes in BMD after follow-up of 5.5 years. To investigate if BMD is altered after switching from immediate- to modified-release $\mathrm{HC}$.

Design and patients: Prospective, observational, longitudinal study with evaluation of BMD by DXA at visit1, after $2.2 \pm 0.4$ (visit2) and after $5.5 \pm 0.8$ years (visit3) included 36 PAI and $8 \mathrm{CAH}$ patients. Thirteen patients received prednisolone (age $52.5 \pm 14.8$ years; 8 women) and 31 patients received immediate-release HC (age $48.9 \pm 15.8$ years; 22 women). Twelve patients on immediate-release switched to modified-release HC at visit2.

Results: Prednisolone showed significantly lower Z-scores compared to $\mathrm{HC}$ at femoral neck $(-0.85 \pm 0.80$ vs $-0.25 \pm 1.16, P<0.05)$, trochanter $(-0.96 \pm 0.62$ vs $0.51 \pm 1.07, P<0.05)$ and total hip $(-0.78 \pm 0.55$ vs $0.36 \pm 1.04, P<0.05)$, but not at lumbar spine, throughout the study. Prednisolone dose decreased by $8 \%$ over study time, but no significant effect was seen on BMD. BMD did not change significantly after switching from immediate- to modified-release HC.

Conclusions: The use of prednisolone as hormone replacement therapy results in significantly lower BMD compared to HC. Patients on low-dose HC replacement therapy showed unchanged Z-scores within the normal reference range during the study period.
\end{abstract}

\author{
Key Words \\ - bone mineral density \\ - hydrocortisone \\ - prednisolone \\ - modified-release \\ hydrocortisone \\ - congenital adrenal \\ hyperplasia
}

Endocrine Connections (2018) 7, 811-818

\section{Introduction}

In states of adrenal insufficiency (AI), such as primary adrenal insufficiency (PAI) and congenital adrenal hyperplasia $(\mathrm{CAH})$, glucocorticoids (GCs) are given in low doses as hormone replacement therapy. However, the daily intake of GCs in PAI and CAH still tends to be more than the total daily endogenous cortisol secretion seen in healthy subjects $\left(5-10 \mathrm{mg}\right.$ of cortisol $/ \mathrm{m}^{2}$ of body surface area/day) (1) possibly triggering long-term morbidities such as osteoporosis. GC-induced decline in bone formation is associated with an increased fracture risk related both to the dose and duration of GC treatment (2). Recent studies on bone mineral density (BMD) in PAI and $\mathrm{CAH}$ patients showed different results. This may be not only due to the often small patient numbers and the 
cross-sectional design, but also due to different disease durations, different GC type and daily dosing. This is highlighted by reduced BMD in all PAI patients in some studies $(3,4)$; however, other studies reported reduced BMD only in men $(7,8)$ or only in postmenopausal women $(5,6)$. Other studies did not find sex differences in BMD $(9,10,11)$. In CAH patients, some studies reported reduced BMD in all or some subpopulations of CAH patients $(18,19,20,21,22,23,24,25,26)$, whereas others described no significant differences in BMD between patients with CAH and controls $(11,12,13,14,15,16,17)$.

Longitudinal studies are scarce: a study including 15 patients with CAH reported an increase in L1-L4 BMD but a decrease of femoral neck BMD after 8-10 years (26); another study including 6 PAIs and 6 secondary AIs also showed a mixed response (27). Recently, we showed that a dose reduction in daily $\mathrm{HC}$ dose resulted in an increase in lumbar spine and total hip BMD in a large cohort of PAI and CAH (28). However, no longitudinal study has examined the effect of different GCs in detail.

Prednisolone is used in approx. 5\% of patients with AI as hormone replacement therapy (29). The Endocrine Society Clinical Practice guideline suggests prednisolone (3-5 mg/day) as an alternative to hydrocortisone (HC), particularly in patients with reduced compliance (30); however, data comparing the safety and efficacy of prednisolone and HC over time are very scarce. Recently, it was demonstrated that AI patients on prednisolone possess a lipid profile, which is associated with a higher risk for cardiovascular disease compared to patients on HC (31). Our group showed in a cross-sectional study setting that AI patients on prednisolone present a worse BMD compared to HC (11).

The aim of this study was to determine if patients on $\mathrm{HC}$ or prednisolone replacement therapy show changes in BMD after follow-up of 5.5 years and to investigate if BMD alters after switching from immediate- to modifiedrelease $\mathrm{HC}$.

\section{Materials and methods}

\section{Design and subjects}

This was a 5-year prospective and observational study including patients from one large endocrine outpatient clinic. Inclusion criteria were PAI or CAH verified by review of the medical records. Patients under the age of 18 years, patients diagnosed with bone metastasis, AI due to longterm pharmacological GC treatment, adrenocortical carcinoma and patients with less than 12-month duration of disease were excluded. The study was approved by the Ethikkommission der Charité - Universitätsmedizin Berlin (EA1/027/10), and all patients gave written informed consent prior to participation.

At study enrolment (visit1), after 2 and 5 years (visit2 and visit3, respectively), BMD was assessed by DXA scan, and all clinical data, including hormone replacement therapies, DHEA and bisphosphonate therapies and changes were documented. Fracture histories were ascertained by self-report, and patients were questioned about fractures they had between 2010 and 2017. Patients were seen every 4-6 months by two experienced endocrinologists (M V and M Q). The endocrinologists had the aim to optimize GC replacement therapy according to best clinical practice guidelines $(32,33,34)$.

Of the included 70 patients, 26 patients had an incomplete data set after 5 years or refused to have a DXA scan at follow-up visits, and therefore, were excluded. For final analysis, there were 36 patients suffering from PAI ( 28 women) and 8 patients with CAH (6 men; salt-wasting $n=7$, simple virilizing $n=1$ ). By the end of 2012, modifiedrelease HC became available for the treatment of patients with AI in Germany. From that time point onwards, AI patients were free to choose which HC regimen they wanted to have. At visit2, 12 of 31 patients on immediaterelease $\mathrm{HC}$ treatment (nine PAIs and three CAHs) decided to switch to modified-release HC (Fig. 1). Due to the different pharmacological profiles between

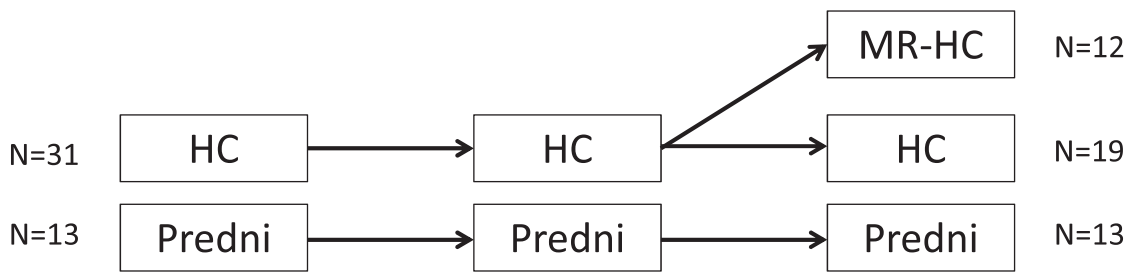

Visit 1

Visit 2 $(2.2 \pm 0.4 \mathrm{yrs})$
Visit 3

$(5.5 \pm 0.8$ yrs $)$
Figure 1

Study design. HC, hydrocortisone; MR-HC, modified-release hydrocortisone; predni, prednisolone.

$$
\text { http://www.endocrineconnections.org }
$$
https://doi.org/10.1530/EC-18-0160
() 2018 The authors Published by Bioscientifica Ltd
This work is licensed under a Creative Commons Attribution-NonCommercial-NoDerivatives 4.0 International License. 
immediate- and modified-release $\mathrm{HC}$, we decided to separately analyze those two groups. For analysis, the dose of GC was converted into milligrams of $\mathrm{HC}$ equivalent ( $1 \mathrm{mg}$ prednisolone $=6 \mathrm{mg} \mathrm{HC}$ ) (35). The daily HC equivalent intake was corrected for body surface area.

\section{Measurements}

Blood was drawn at visit1 (baseline) and at follow-up visits (visit 2 and 3) for measurement of the following parameters: serum calcium $(\mathrm{Ca}$; Roche Diagnostics $\mathrm{GmbH})$, phosphorus (P; Roche Diagnostics $\mathrm{GmbH}$ ), alkaline phosphatase (AP; Roche Diagnostics $\mathrm{GmbH}$ ), parathyroid hormone (PTH; Elecsys-PTH, Roche Diagnostics $\mathrm{GmbH})$ and 25-hydroxyvitamin D3 $(25(\mathrm{OH})$ D3; IDS-ISYS immunoassay; Immunodiagnostic Systems (IDS) GmbH, Frankfurt, Germany).

BMD was measured using dual energy X-ray absorptiometry (DXA) (GE Lunar DPX-NT, Madison, WI, USA) at total hip, lumbar spine (L1-L4), femoral neck and greater trochanter. The manufacturer's standard scan and positioning protocols were adhered to. Spine phantom quality control scans were performed daily during the study, and phantom data were entered into a Shewhart chart with a previously established baseline (the mean of ten initial control scans). The control scans were always within $\pm 1.5 \%$ from the initial mean, and the precision error was S.D. $0.004 \mathrm{~g} / \mathrm{cm}^{2}$, CV $0.414 \%$ or below. Scans were analyzed using GE-Lunar software version enCORE 2004. The results were transformed into Z-scores using sex- and age-matched reference data provided by the manufacturer originating from an American population.

\section{Statistical analysis}

BMD is expressed by Z-scores, which represent ageand gender-adjusted standard deviation score (SDS), which are presented as means with 95\% CIs. This was derived from quality controls performed according to manufacturer's standards, as described in the manuals of standard operating procedures. CI different from zero indicates Z-scores statistically different from the reference population. A T-score value below -2.5 s.D. was defined as osteoporosis.

Comparisons between two groups were made using the unpaired $t$-test when values were normally distributed. Otherwise, the Mann-Whitney rank-sum test was used. When continuous variables were compared in all three groups, one-way ANOVA was used for normal distributions. In cases of non-normal distribution the
Kruskal-Wallis test was performed. Chi-square was used for calculations of frequency. When the expected frequency was small $(n<5)$, the Fisher's exact test was used. Analyses were performed using the statistical software package SPSS, version 22.0 (SPSS Inc). Significance was accepted if $P<0.05$.

\section{Results}

Clinical data of our study cohort at visit 1 is shown in Table 1. There were no significant differences in age, BMI, duration of disease, calcium, phosphorus, alkaline phosphatase, 25-hydroxyvitamin D3 or parathyroid hormone between AI patients on $\mathrm{HC}$ or prednisolone therapy (Table 1). Furthermore, there were no significant differences in BMI, serum calcium, serum phosphate, alkaline phosphatase, parathyroid hormone and 25-hydroxyvitamin D3 between the treatment groups during the whole study period (data not shown).

Patients on prednisolone showed significantly lower Z-scores at femoral neck $(-0.85 \pm 0.80$ vs $-0.25 \pm 1.16$, $P<0.05)$, trochanter $(-0.96 \pm 0.62$ vs $0.51 \pm 1.07, P<0.05)$ and total hip $(-0.78 \pm 0.55$ vs $0.36 \pm 1.04, P<0.05)$ at all visits during the study period (Fig. 2 and Table 2). However, Z-scores at lumbar spine (L1-L4) were not significantly different between the treatment groups at visit1 and throughout the study. Also T-scores were significant lower at femoral neck, trochanter and at total hip, but not at lumbar spine, in AI patients on prednisolone compared to patients on HC (Table 2).

Prednisolone doses decreased by $8 \%$ over study time (mean 5.47-5.05 mg/day), but no significant effect was seen on BMD. HC doses remained unchanged during the study period, and BMD did not alter during the study period in subjects on HC medication. Furthermore, BMD did not change significantly after switching from immediate- to modified-release $\mathrm{HC}$ in AI patients (visit3 vs visit2) (Fig. 2 and Table 2). There was no significant difference in Z-scores or T-scores between immediate- and modified-release HC at visit3 (Table 2).

The diagnosis of osteoporosis was not significantly different among the three treatment groups (Table 3). Also the frequency of bisphosphonate therapy or DHEA therapy was not significantly different between the groups. Several fractures appeared throughout the study period from 2010 to 2017, showing the highest number of fractures in the prednisolone group (Table 3). Fractures associated with road traffic accidents or skiing accidents are usually not regarded as osteoporosis associated fractures and 
Table 1 Clinical data at visit1 (study start) in patients with PAI or CAH separated into different GC groups.

\begin{tabular}{|c|c|c|c|}
\hline & \multicolumn{3}{|c|}{ Visit 1} \\
\hline & Always on immediate-release $\mathrm{HC}$ & $\begin{array}{c}\text { Immediate-release } \mathrm{HC} \text { (switch to } \\
\text { modified-release } \mathrm{HC} \text { at visit 2) }\end{array}$ & Prednisolone \\
\hline$n(\mathrm{PAl} / \mathrm{CAH})$ & $19(17 / 2)$ & $12(9 / 3)$ & $13(10 / 3)$ \\
\hline Sex (men/women) & $6 / 13$ & $3 / 9$ & $5 / 8$ \\
\hline Postmenopausal status (women) & $9 / 13$ & $4 / 9$ & $5 / 8$ \\
\hline Age (years) & $49.6 \pm 16.9$ & $47.8 \pm 14.5$ & $52.5 \pm 14.8$ \\
\hline $\mathrm{BMI}\left(\mathrm{kg} / \mathrm{m}^{2}\right)$ & $26.3 \pm 4.9$ & $24.3 \pm 2.2$ & $26.5 \pm 4.6$ \\
\hline Duration of disease (years) & $19.2 \pm 11.6$ & $17.4 \pm 11.3$ & $23.5 \pm 11.8$ \\
\hline Daily HC-equivalent dose (mg) & $24.2 \pm 6.1$ & $21.1 \pm 5.1$ & $32.7 \pm 11.3^{a, b b}$ \\
\hline GC dose per body surface $\left(\mathrm{mg} / \mathrm{m}^{2}\right)$ & $13.2 \pm 3.1$ & $12.1 \pm 2.9$ & $17.9 \pm 5.7^{\mathrm{a}, \mathrm{b}}$ \\
\hline Calcium (2.15-2.65 mmol/L) & $2.32 \pm 0.08$ & $2.33 \pm 0.07$ & $2.26 \pm 0.1$ \\
\hline Phosphorus (0.8-1.5 mmol/L) & $0.90 \pm 0.17$ & $0.90 \pm 0.17$ & $0.9 \pm 0.1$ \\
\hline Alkaline phosphatase (35-104 U/L) & $54.7 \pm 12.4$ & $52.3 \pm 14.2$ & $55.5 \pm 15.4$ \\
\hline Parathyroid hormone (11-67 pg/mL) & $35.6 \pm 27.5$ & $36.1 \pm 9.6$ & $32.4 \pm 14.5$ \\
\hline 25-Hydroxyvitamin $\mathrm{D}_{3}(50-250 \mathrm{nmol} / \mathrm{L})$ & $61.4 \pm 22.7$ & $62.7 \pm 27.3$ & $52.8 \pm 19.1$ \\
\hline
\end{tabular}

Means \pm S.D. For analysis, the dose of GC was converted into milligrams of HC equivalent (1 mg prednisolone $=6 \mathrm{mg}$ hydrocortisone). When continuous variables were compared in all three groups, one-way ANOVA was used for normal distributions. In cases of non-normal distribution the Kruskal-Wallis test was performed. Chi-square was used for calculations of frequency. When the expected frequency was small $(n<5)$, the Fisher's exact test was used. ${ }^{a} P<0.05$ to immediate-release $\mathrm{HC} ;{ }^{b} P<0.05,{ }^{b}{ }^{b} P<0.01$ to immediate-release $\mathrm{HC}$ (switch to modified-release $\mathrm{HC}$ at visit2). $\mathrm{CAH}$, congenital adrenal hyperplasia; GC, glucocorticoid; HC, hydrocortisone; PAI, primary adrenal insufficiency.

might be excluded. This would results in fractures in 2 of 19 patients in the immediate-release HC group, 0 of 12 in the modified-release HC group and 3 of 13 patients in the prednisolone group. Even when analyzing all patients on HC $(n=31)$ vs patients on prednisolone $(n=13)$, there was no significant difference in frequency of fractures $(P=0.144)$

\section{Discussion}

GC therapy using pharmacological doses has a detrimental effect on bone, which is known to be strongly dose dependent. Also in hormone replacement, it is known that doses of $30 \mathrm{mg} \mathrm{HC}$ daily have negative effects on bone, and a dose-relationship was described (4). However, at low doses of $20 \mathrm{mg} \mathrm{HC}$ daily, no differences in BMD could be observed compared to healthy controls (11). Recently, we were able to show that a dose reduction in even low daily HC doses resulted in an increase in lumbar spine and total hip BMD in a large cohort of PAI and CAH (28). This strongly suggests that the previously seen detrimental effects of GC replacement therapy in PAI were primarily a consequence of supraphysiological GC exposure. These data emphasize the need to aim for the lowest possible HC replacement dose in $\mathrm{AI}$ patients that maintains health and avoids the development of long-term adverse effects such as decreased BMD.

In contrast to the predominant use of $\mathrm{HC}$ by patients in Europe and the United States, many PAI patients in other regions of the world are prescribed oral prednisolone

$$
\begin{array}{lr}
\text { http://www.endocrineconnections.org } & \text { () } 2018 \text { The authors } \\
\text { https://doi.org/10.1530/EC-18-0160 } & \text { Published by Bioscientifica Ltd }
\end{array}
$$

in view of its ease of administration, low cost and easy availability (36), however, often in too high doses, e.g. $7.5 \mathrm{mg}$ /day (37). A dose of $5 \mathrm{mg}$ /day prednisolone, given to healthy volunteers, has been shown to significantly impair markers of bone formation and, to a lesser extent, bone resorption markers (38). Recent data suggest that prednisolone is deleterious for BMD even when used in low doses for hormone replacement therapy in AI $(11,18$, $28,36,39)$.

This study is the first prospective and longitudinal study in AI investigating the impact of prednisolone on BMD over a longer period of more than 5 years. We found significantly reduced BMD at femoral neck,

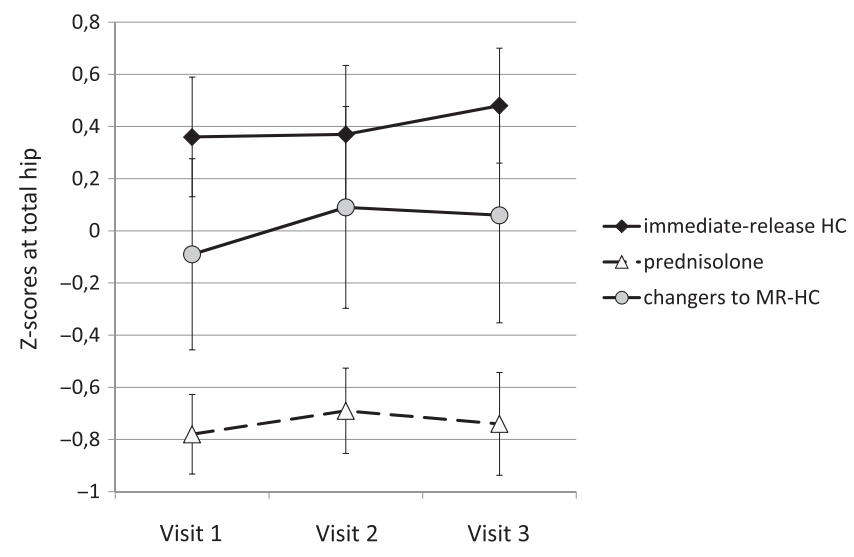

Figure 2

Z-scores at total hip of patients with primary adrenal insufficiency on immediate-release or MR-HC or prednisolone over the study period of 5.5 years. Means \pm S.E.M. HC, hydrocortisone; MR-HC, modified-release hydrocortisone; predni, prednisolone. 
Table 2 Bone mineral density (BMD) at (a) visit1 (start of the study), at (b) visit2 (after $2.2 \pm 0.4$ years) and at (c) visit3 (after $5.5 \pm 0.8$ years) in patients with PAI or CAH divided into different GC groups.

\begin{tabular}{|c|c|c|c|}
\hline & Always on immediate-release HC & $\begin{array}{l}\text { Immediate-release } \mathbf{H C} \\
\text { (switch to modified-release HC at visit 2) }\end{array}$ & Prednisolone \\
\hline \multicolumn{4}{|l|}{ (a) Visit1 } \\
\hline Z-score lumbar spine (L1-L4) & $-0.26 \pm 0.89$ & $-0.51 \pm 1.12$ & $-0.58 \pm 1.14$ \\
\hline Z-score femoral neck & $0.25 \pm 1.16$ & $-0.07 \pm 1.20$ & $-0.85 \pm 0.80^{\mathrm{aa}, \mathrm{b}}$ \\
\hline Z-score greater trochanter & $0.51 \pm 1.07$ & $0.18 \pm 1.53$ & $-0.96 \pm 0.62^{\mathrm{aa}, \mathrm{b}}$ \\
\hline Z-score total hip & $0.36 \pm 1.04$ & $-0.09 \pm 1.27$ & $-0.78 \pm 0.55^{\mathrm{aa}}$ \\
\hline T-score lumbar spine (L1-L4) & $-0.84 \pm 1.10$ & $-0.91 \pm 1.21$ & $-1.12 \pm 1.30$ \\
\hline T-score femoral neck & $-0.32 \pm 1.30$ & $-0.61 \pm 1.27$ & $-1.48 \pm 1.02^{\mathrm{a}}$ \\
\hline T-score greater trochanter & $0.26 \pm 1.09$ & $-0.08 \pm 1.41$ & $-1.20 \pm 0.80^{\mathrm{b}, \mathrm{aaa}}$ \\
\hline T-score total hip & $-0.03 \pm 1.14$ & $-0.52 \pm 1.20$ & $-1.27 \pm 0.74^{\text {aа }}$ \\
\hline \multicolumn{4}{|l|}{ (b) Visit2 } \\
\hline Z-score lumbar spine (L1-L4) & $-0.22 \pm 0.86$ & $-0.40 \pm 1.35$ & $-0.42 \pm 1.16$ \\
\hline Z-score femoral neck & $0.26 \pm 1.20$ & $-0.12 \pm 1.19$ & $-0.62 \pm 0.64^{\mathrm{a}}$ \\
\hline Z-score greater trochanter & $0.43 \pm 1.34$ & $0.28 \pm 1.61$ & $-0.81 \pm 0.72^{\mathrm{aa}, \mathrm{b}}$ \\
\hline Z-score total hip & $0.34 \pm 1.15$ & $0.09 \pm 1.34$ & $-0.69 \pm 0.59^{a a, b}$ \\
\hline T-score lumbar spine (L1-L4) & $-0.87 \pm 0.97$ & $-0.84 \pm 1.33$ & $-1.09 \pm 1.24$ \\
\hline T-score femoral neck & $-0.44 \pm 1.37$ & $-0.73 \pm 1.16$ & $-1.45 \pm 0.74^{\mathrm{a}}$ \\
\hline T-score greater trochanter & $-0.28 \pm 2.36$ & $-0.03 \pm 1.44$ & $-1.21 \pm 0.76^{b}$ \\
\hline T-score total hip & $-0.19 \pm 1.24$ & $-0.38 \pm 1.25$ & $-1.36 \pm 0.68^{\mathrm{aa}, \mathrm{b}}$ \\
\hline \multicolumn{4}{|l|}{ (c) Visit3 } \\
\hline Z-score lumbar spine (L1-L4) & $-0.14 \pm 1.16$ & $-0.39 \pm 1.47$ & $-0.18 \pm 0.59$ \\
\hline Z-score femoral neck & $0.26 \pm 0.99$ & $-0.30 \pm 1.22$ & $-0.71 \pm 0.73^{\mathrm{aa}}$ \\
\hline Z-score greater trochanter & $0.46 \pm 1.13$ & $0.11 \pm 1.90$ & $-1.07 \pm 0.72^{\mathrm{aa}}$ \\
\hline Z-score total hip & $0.48 \pm 0.96$ & $0.06 \pm 1.43$ & $-0.74 \pm 0.71^{\text {aa }}$ \\
\hline T-score lumbar spine (L1-L4) & $-0.67 \pm 1.04$ & $-0.89 \pm 1.47$ & $-1.15 \pm 1.02$ \\
\hline T-score femoral neck & $-0.55 \pm 1.42$ & $-1.11 \pm 1.43$ & $-1.89 \pm 0.74^{\text {aа }}$ \\
\hline T-score greater trochanter & $0.06 \pm 1.24$ & $-0.38 \pm 1.73$ & $-1.91 \pm 0.84^{\text {b, aaa }}$ \\
\hline T-score total hip & $-0.16 \pm 1.20$ & $-0.50 \pm 1.47$ & $-1.58 \pm 0.84^{a a, b}$ \\
\hline
\end{tabular}

Z-scores represent age and gender-adjusted SDS. Means \pm s.D. When continuous variables were compared in all three groups, one-way ANOVA was used for normal distributions. In cases of non-normal distribution the Kruskal-Wallis test was performed.

a $P<0.05$, aa $P<0.01$, aaa $P<0.001$ to immediate-release $\mathrm{HC}$; ${ }^{\mathrm{b}} P<0.05$, bb $P<0.01$ to immediate-release $\mathrm{HC}$ (switch to modified-release $\mathrm{HC}$ at visit2).

$\mathrm{CAH}$, congenital adrenal hyperplasia; GC, glucocorticoid; HC, hydrocortisone; PAl, primary adrenal insufficiency.

greater trochanter and total hip, but not at lumbar spine, in patients on a long-term replacement therapy with prednisolone compared to those on HC. Surprisingly, those patients did not display any difference in BMI suggesting that the bone, especially femur and hip, is more sensitive to this long-acting synthetic GC than other tissues and a better long-time marker for GC exposure. The often used relative biological potency and conversion rate of $\mathrm{HC}$ and prednisolone was calculated using the ACTH-suppressive effect (40) resulting in a 1:4 conversion rate. However, the effects of prednisolone on growth in $\mathrm{CAH}$ children result in a suggested conversion rate of 6-8:1 (35).

Our data endorse cross-sectional data from Swedish $\mathrm{CAH}$ patients who presented lower femoral and lumbar BMD and more severe fractures when receiving prednisolone (39). Also in a cohort from India with 41 PAI patients, prednisolone resulted in a decreased BMD (36). In our study, the two treating physicians tried to reduce the prednisolone doses during the study period. They achieved a dose reduction of $8 \%$, and it was documented

$$
\begin{array}{lr}
\text { http://www.endocrineconnections.org } & \text { ○ } 2018 \text { The authors } \\
\text { https://doi.org/10.1530/EC-18-0160 } & \text { Published by Bioscientifica Ltd }
\end{array}
$$

that a further reduction was often not tolerated from patient's side. However, the aim should be a further dose reduction to $3-5 \mathrm{mg} /$ day in those patients who are not willing to change prednisolone. Due to the long study period, we were able to document all fractures occurring during that time (2010 to 2017). It is noteworthy that the worst fractures appeared in the prednisolone group; however, the frequency of fractures was not statistically different between HC-treated patients and patients receiving prednisolone. However, this might be also due to our small cohort size and further investigations are warrant in larger cohorts.

In our study, we showed that HC replacement therapy seems to be safe regarding bone health when used in standard replacement doses. BMD remained stable over a long treating period of 5.5 years. Also the change from immediate-release to modified-release HC seemed to be safe and did not worsen BMD. In the group of patients with modified-release HC no spontaneous fractures appeared during the study period. In a recent, longitudinal study,

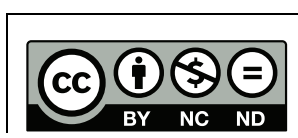

This work is licensed under a Creative Commons Attribution-NonCommercial-NoDerivatives 4.0 International License. 
Table 3 Clinical data, concomitant medications and fractures in patients with adrenal insufficiency separated into different glucocorticoid replacement groups during study period 2010-2017.

\begin{tabular}{|c|c|c|c|}
\hline & Immediate-release HC $(n=19)$ & Modified-release HC $(n=12)$ & Prednisolone $(n=13)$ \\
\hline Diagnosis osteoporosis & $4 / 19$ & $3 / 12$ & $4 / 13$ \\
\hline Therapy with bisphosphonate & $4 / 19$ & $1 / 12$ & $3 / 13$ \\
\hline DHEA therapy (women) & $5 / 13$ & $3 / 9$ & $5 / 8$ \\
\hline Sex steroid HRT (women) & $3 / 13$ & $2 / 9$ & $1 / 8$ \\
\hline $\begin{array}{l}\text { Fractures during study period } \\
2010-2017\end{array}$ & $\begin{array}{l}\text { 2/19: } \\
\text { - Radius fracture 12-2011 } \\
\text { - Hand wrist fracture 7-2010 and } \\
\text { ulnar fracture 10-2011 }\end{array}$ & $\begin{array}{l}\text { 1/12: } \\
\text { - Os pubis fracture due to } \\
\text { motorcycle accident } 6-2010\end{array}$ & $\begin{array}{l}\text { 4/13: } \\
\text { - Metatarsal fracture 5-2015 } \\
\text { - Lumbal vertebral body } 2 \\
\text { fracture } 11-2015 \\
\text { - Lumbal vertebral body } 8 \\
\text { and } 11 \text { fracture } 2010 \\
\text { - Proximal femur fracture } \\
\text { left 3-2013 due to skiing } \\
\text { accident }\end{array}$ \\
\hline
\end{tabular}

Chi-square was used for calculations of frequency. When the expected frequency was small $(n<5)$, the Fisher's exact test was used.

$\mathrm{HC}$, hydrocortisone; HRT, hormone replacement therapy.

14 patients with secondary AI (ten females: median age 55 years, range 31-77 years) who had used conventional GC regimens for at least 12 months were changed to modified-release HC (41). After 24 months of treatment with modified-release $\mathrm{HC}$, a significant increase in BMD values at lumbar spine and femoral neck was observed, without statistically significant change in total hip BMD.

Our study has a number of limitations. In general, the patient cohort was heterogeneous in terms of etiology of PAI and forms of CAH. Subgroups were too small for further subanalysis of PAI and CAH. Also the presence or absence of bisphosphonate and/or DHEA therapy might play a role as confounder, especially due to the fact that the lowest proportion of patients on bisphosphonate therapy occurred in the modified-release HC group and the highest proportion of patients on DHEA therapy occurred in the prednisolone group. Furthermore, this study was not randomized and consisted of only 44 patients. We cannot exclude influences of previous GC replacement regimens before study inclusion on the current BMD status of your cohort, especially episodes in the 1990s and 2000s - years when higher doses of GC replacement therapy were commonly used.

In summary, we showed that prednisolone seems to be worse for BMD at femur and hip in doses commonly used in hormone replacement therapy for AI (e.g. $5 \mathrm{mg} /$ day). Therefore, patients should be switched either to HC therapy or prednisolone should be at least further reduced to doses of 3-4 mg/day.

\section{Declaration of interest}

Marcus Quinkler and Kathrin Zopf received honoraria for talks and consultancy from Viropharma/Shire; Tina Kienitz received honoraria for consultancy from Viropharma/Shire.

$\begin{array}{lr}\text { http://www.endocrineconnections.org } & \text { ○ } 2018 \text { The authors } \\ \text { https://doi.org/10.1530/EC-18-0160 } & \text { Published by Bioscientifica Ltd }\end{array}$

\section{Funding}

This work did not receive any specific grant from any funding agency in the public, commercial, or not-for-profit sector.

\section{References}

1 Esteban NV, Loughlin T, Yergey A, Zawadzki JK, Booth JD, Winterer JC \& Loriaux DL. Daily cortisol production rate in man determuned by stable isotope dilution/mass spectrometry. Journal of Clinical Endocrinology and Metabolism 199172 39-45. (https://doi. org/10.1210/jcem-72-1-39)

2 Angeli A, Guglielmi G, Dovio A, Capelli G, de Feo, D, Giannini S, Giorgino R, Moro L \& Giustina A. High prevalence of asymptomatic vertebral fractures in post-menopausal women receiving chronic glucocorticoid therapy: a cross-sectional outpatient study. Bone 2006 39 253-259. (https://doi.org/10.1016/j.bone.2006.02.005)

3 Heureux F, Maiter D, Boutsen Y, Devogelaer JP, Jamart J \& Donckier J. Evaluation of corticosteroid replacement therapy and its effect on bones in Addison's disease. Annales d'Endocrinologie 200061 179-183.

4 Lovas K, Gjesdal CG, Christensen M, Wolff AB, Almås B, Svartberg J, Fougner KJ, Syversen U, Bollerslev J, Falch JA, et al. Glucocorticoid replacement therapy and pharmacogenetics in Addison's disease: effects on bone. European Journal of Endocrinology 2009160 993-1002. (https://doi.org/10.1530/EJE-08-0880)

5 Devogelaer JP, Crabbe J \& de Nagant DC. Bone mineral density in Addison's disease: evidence for an effect of adrenal androgens on bone mass. BMJ 1987294 798-800. (https://doi.org/10.1136/ bmj.294.6575.798)

6 Valero MA, Leon M, Ruiz Valdepenas MP, Larrodera L, Lopez MB, Papapietro K, Jara A \& Hawkins F. Bone density and turnover in Addison's disease: effect of glucocorticoid treatment. Bone and Mineral 199426 9-17. (https://doi.org/10.1016/S01696009(08)80158-4)

7 Zelissen PM, Croughs RJ, van Rijk PP \& Raymakers JA. Effect of glucocorticoid replacement therapy on bone mineral density in patients with Addison disease. Annals of Internal Medicine 1994120 207-210. (https://doi.org/10.7326/0003-4819-120-3-19940201000005)

8 Braatvedt GD, Joyce M, Evans M, Clearwater J \& Reid IR. Bone mineral density in patients with treated Addison's disease. Osteoporosis International 199910 435-440. (https://doi.org/10.1007/ s001980050251)

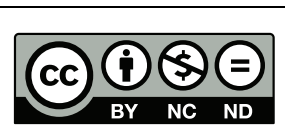
This work is licensed under a Creative Commons
Attribution-NonCommercial-NoDerivatives 4.0 International License. 
9 Jodar E, Valdepenas MP, Martinez G, Jara A, Hawkins F. Long-term follow-up of bone mineral density in Addison's disease. Clinical Endocrinology 200358 617-620. (https://doi.org/10.1046/j.13652265.2003.01761.x)

10 Arlt W, Rosenthal C, Hahner S \& Allolio B. Quality of glucocorticoid replacement in adrenal insufficiency: clinical assessment vs. timed serum cortisol measurements. Clinical Endocrinology $2006 \mathbf{6 4}$ 384-389.

11 Koetz KR, Ventz M, Diederich S \& Quinkler M. Bone mineral density is not significantly reduced in adult patients on low-dose glucocorticoid replacement therapy. Journal of Clinical Endocrinology and Metabolism 201297 85-92. (https://doi.org/10.1210/jc.2011-2036)

12 Guo CY, Weetman AP \& Eastell R. Bone turnover and bone mineral density in patients with congenital adrenal hyperplasia. Clinical Endocrinology 199645 535-541. (https://doi.org/10.1046/j.13652265.1996.00851.x)

13 Gussinye M, Carrascosa A, Potau N, Enrubia M, Vicens-Calvet E Ibanez L \& Yeste D. Bone mineral density in prepubertal and in adolescent and young adult patients with the salt-wasting form of congenital adrenal hyperplasia. Pediatrics 1997100 671-674. (https://doi.org/10.1542/peds.100.4.671)

14 Mora S, Saggion F, Russo G, Weber G, Bellini A, Prinster C \& Chiumello $\mathrm{G}$. Bone density in young patients with congenital adrenal hyperplasia. Bone 199618 337-340. (https://doi. org/10.1016/8756-3282(96)00003-8)

15 Stikkelbroeck NM, Oyen WJ, van der Wilt GJ, Hermus AR \& Otten BJ. Normal bone mineral density and lean body mass, but increased fat mass, in young adult patients with congenital adrenal hyperplasia. Journal of Clinical Endocrinology and Metabolism 200388 1036-1042. (https://doi.org/10.1210/jc.2002-021074)

16 Girgis R \& Winter JS. The effects of glucocorticoid replacement therapy on growth, bone mineral density, and bone turnover markers in children with congenital adrenal hyperplasia. Journal of Clinical Endocrinology and Metabolism 199782 3926-3929. (https:// doi.org/10.1210/jcem.82.12.4320)

17 Christiansen P, Molgaard C \& Muller J. Normal bone mineral content in young adults with congenital adrenal hyperplasia due to 21-hydroxylase deficiency. Hormone Research 200461 133-136.

18 Jaaskelainen J \& Voutilainen R. Bone mineral density in relation to glucocorticoid substitution therapy in adult patients with 21-hydroxylase deficiency. Clinical Endocrinology 199645 707-713. (https://doi.org/10.1046/j.1365-2265.1996.8620871.x)

19 Hagenfeldt K, Martin RE, Ringertz H, Helleday J \& Carlstrom K. Bone mass and body composition of adult women with congenital virilizing 21-hydroxylase deficiency after glucocorticoid treatment since infancy. European Journal of Endocrinology 2000143 667-671. (https://doi.org/10.1530/eje.0.1430667)

20 Cameron FJ, Kaymakci B, Byrt EA, Ebeling PR, Warne GL \& Wark JD Bone mineral density and body composition in congenital adrenal hyperplasia. Journal of Clinical Endocrinology and Metabolism $1995 \mathbf{8 0}$ 2238-2243. (https://doi.org/10.1210/jcem.80.7.7608286)

21 de Almeida Freire PO, de Lemos-Marini SH, Maciel-Guerra AT, Morcillo AM, Matias Baptista MT, de Mello MP \& Guerra G Jr. Classical congenital adrenal hyperplasia due to 21-hydroxylase deficiency: a cross-sectional study of factors involved in bone mineral density. Journal of Bone and Mineral Metabolism 200321 396-401. (https://doi.org/10.1007/s00774-003-0434-6)

22 King JA, Wisniewski AB, Bankowski BJ, Carson KA, Zacur HA $\&$ Migeon CJ. Long-term corticosteroid replacement and bone mineral density in adult women with classical congenital adrenal hyperplasia. Journal of Clinical Endocrinology and Metabolism 200691 865-869. (https://doi.org/10.1210/jc.2005-0745)

23 Sciannamblo M, Russo G, Cuccato D, Chiumello G \& Mora S. Reduced bone mineral density and increased bone metabolism rate in young adult patients with 21-hydroxylase deficiency. Journal of
Clinical Endocrinology and Metabolism 200691 4453-4458. (https:// doi.org/10.1210/jc.2005-2823)

24 Falhammar H, Filipsson H, Holmdahl G, Janson PO, Nordenskjold A, Hagenfeldt $\mathrm{K} \&$ Thoren M. Fractures and bone mineral density in adult women with 21-hydroxylase deficiency. Journal of Clinical Endocrinology and Metabolism 200792 4643-4649. (https://doi. org/10.1210/jc.2007-0744)

25 Zimmermann A, Sido PG, Schulze E, Al KC, Lazea C, Coldea C \& Weber MM. Bone mineral density and bone turnover in Romanian children and young adults with classical 21-hydroxylase deficiency are influenced by glucocorticoid replacement therapy. Clinical Endocrinology 200971 477-484. (https://doi.org/10.1111/j.13652265.2008.03518.x

26 Ceccato F, Barbot M, Albiger N, Zilio M, De Toni P, Luisetto G, Zaninotto M, Greggio NA, Boscaro M, Scaroni C, et al. Long-term glucocorticoid effect on bone mineral density in patients with congenital adrenal hyperplasia due to 21-hydroxylase deficiency. European Journal of Endocrinology 2016175 101-106. (https://doi. org/10.1530/EJE-16-0104)

27 Peacey SR, Yuan GC, Eastell R \& Weetman AP. Optimization of glucocorticoid replacement therapy: the long-term effect on bone mineral density. Clinical Endocrinology 199950 815-817. (https://doi. org/10.1046/j.1365-2265.1999.00787.x)

28 Schulz J, Frey KR, Cooper MS, Zopf K, Ventz M, Diederich S \& Quinkler M. Reduction in daily hydrocortisone dose improves bone health in primary adrenal insufficiency. European Journal of Endocrinology 2016174 531-538. (https://doi.org/10.1530/EJE-151096)

29 Murray RD, Ekman B, Uddin S, Marelli C, Quinkler M \& Zelissen PM. Management of glucocorticoid replacement in adrenal insufficiency shows notable heterogeneity - data from the EU-AIR. Clinical Endocrinology 201786 340-346. (https://doi.org/10.1111/cen.13267)

30 Bornstein SR, Allolio B, Arlt W, Barthel A, Don-Wauchope A, Hammer GD, Husebye ES, Merke DP, Murad MH, Stratakis CA et al. Diagnosis and treatment of primary adrenal insufficiency: an Endocrine Society Clinical Practice Guideline. Journal of Clinical Endocrinology and Metabolism 2016101 364-389. (https://doi. org/10.1210/jc.2015-1710)

31 Quinkler M, Ekman B, Marelli C, Uddin S, Zelissen P \& Murray RD. Prednisolone is associated with a worse lipid profile than hydrocortisone in patients with adrenal insufficiency. Endocrine Connections 20176 1-8. (https://doi.org/10.1530/EC-16-0081)

32 Husebye ES, Allolio B, Arlt W, Badenhoop K, Bensing S, Betterle C, Falorni A, Gan EH, Hulting AL, Kasperlik-Zaluska A, et al. Consensus statement on the diagnosis, treatment and follow-up of patients with primary adrenal insufficiency. Journal of Internal Medicine 2014275 104-115. (https://doi.org/10.1111/joim.12162)

33 Auchus RJ \& Arlt W. Approach to the patient: the adult with congenital adrenal hyperplasia. Journal of Clinical Endocrinology and Metabolism 201398 2645-2655. (https://doi.org/10.1210/jc.20131440)

34 Grossman A, Johannsson G, Quinkler M \& Zelissen P. Therapy of endocrine disease: perspectives on the management of adrenal insufficiency: clinical insights from across Europe. European Journal of Endocrinology 2013169 R165-R175. (https://doi.org/10.1530/EJE-130450)

35 Caldato MC, Fernandes VT \& Kater CE. One-year clinical evaluation of single morning dose prednisolone therapy for 21-hydroxylase deficiency. Arquivos Brasileiros de Endocrinologia e Metabologia 200448 705-712. (https://doi.org/10.1590/S0004-27302004000500017)

36 Chandy DD \& Bhatia E. Bone mineral density in patients with addison disease on replacement therapy with prednisolone. Endocrine Practices 201622 434-439.

37 Hong AR, Ryu OH, Kim SY \& Kim SW. Characteristics of korean patients with primary adrenal insufficiency: a registry-based http://www.endocrineconnections.org

https://doi.org/10.1530/EC-18-0160
C 2018 The authors Published by Bioscientifica Ltd
This work is licensed under a Creative Commons Attribution-NonCommercial-NoDerivatives 4.0 International License. 
nationwide survey in Korea. Endocrinology and Metabolism 201732 466-474. (https://doi.org/10.3803/EnM.2017.32.4.466)

38 Ton FN, Gunawardene SC, Lee H \& Neer RM. Effects of low-dose prednisone on bone metabolism. Journal of Bone and Mineral Research 200520 464-470. (https://doi.org/10.1359/JBMR.041125)

39 Falhammar H, Filipsson NH, Wedell A, Brismar K \& Thoren M. Bone mineral density, bone markers, and fractures in adult males with congenital adrenal hyperplasia. European Journal of Endocrinology 2013168 331-341. (https://doi.org/10.1530/EJE-12-0865)
40 Khalid BA, Burke CW, Hurley DM, Funder JW \& Stockigt JR. Steroid replacement in Addison's disease and in subjects adrenalectomized for Cushing's disease: comparison of various glucocorticoids. Journal of Clinical Endocrinology and Metabolism 198255 551-559. (https:// doi.org/10.1210/jcem-55-3-551)

41 Frara S, Chiloiro S, Porcelli T, Giampietro A, Mazziotti G, De ML \& Giustina A. Bone safety of dual-release hydrocortisone in patients with hypopituitarism. Endocrine 201860 528-531. (https://doi. org/10.1007/s12020-017-1512-1)

Received in final form 30 April 2018

Accepted 2 May 2018

Accepted Preprint published online 2 May 2018
This work is licensed under a Creative Commons Attribution-NonCommercial-NoDerivatives 4.0 International License. 